\title{
ELEIÇÃO E FORMAÇÃO DE DIRETORES DE ESCOLAS MUNICIPAIS: A LEGISLAÇÃ O E AS PRÁTICAS DA REDE MUNICIPAL DE ENSINO DE PONTA GROSSA
}

\author{
Teresa Jussara Luporini \\ Centro Universitário Católico do Sudoeste do Paraná.- UNICS \\ Secretaria Municipal de Educação de Ponta Grossa- SMEPG \\ Vera Lúcia Martiniak \\ Universidade Estadual de Ponta Grossa - UEPG \\ Secretaria Municipal de Educação de Ponta Grossa- SMEPG \\ Zélia Maria Lopes Marochi \\ Universidade Estadual de Ponta Grossa - UEPG \\ Secretaria Municipal de Educação de Ponta Grossa- SMEPG
}

\begin{abstract}
RESUMO
A eleição de diretores tem-se revelado tema polêmico e desafiador no contexto das políticas educacionais. $\mathrm{O}$ presente trabalho pretende discutir como ocorre a formação continuada de professores que assumem as diferentes atribuições de gestores em nível de sistema e das unidades escolares assim como a experiência realizada no sistema escolar de ensino de Ponta Grossa-PR, descrevendo a sistemática de seleção de diretores para atuar em escolas dos anos iniciais. A metodologia utilizada, sob a forma de aplicação de questionários e acompanhamento da formação continuada por meio de grupo de estudo mensal, revelam práticas do cotidiano escolar que se colocam como desafios na atuação dos diretores da referida rede municipal de ensino.

Palavras-chave: gestão educacional; eleição de diretores escolares; seleção de diretores escolares
\end{abstract}

\section{ELECTION AND FORMATION OF DIRECTORS OF MUNICIPAL SCHOOLS: THE LAW AND PRACTICE IN THE SCHOOL SYSTEM OF PONTA GROSSA}

\begin{abstract}
The election of directors has proved controversial and challenging issue in the context of education policy. This paper aims to discuss how does the continuing education of teachers who take the different roles of managers at the system level and school units performed as well as experience teaching in the school system of Ponta Grossa, PR, describing the systematic selection of directors schools to act in the early years. The methodology used in the form of questionnaires and monitoring of continuing education through monthly study group, show the daily school practices facing challenges in acting as directors of the said municipal schools.

Keywords: educational administration, the election of school directors, selection of school principals
\end{abstract}




\section{Introdução}

A eleição de diretores tem-se revelado tema polêmico e desafiador no contexto das políticas educacionais.

A literatura especializada na área aponta diferentes posicionamentos sobre o tema.

Historicamente, a indicação de diretores tem sido tratada no Brasil, como prerrogativa do Poder Executivo, seja municipal seja estadual.

O advento das eleições para ocupar a função de diretor de unidade escolar ocorreu nos anos 80, no interior da retomada do contexto democrático no país. O Estado do Paraná ocupa lugar de destaque, neste panorama, pois foi um dos primeiros estados que adotou a prática.

Nos últimos 20 anos o processo de eleição de diretores foi tema de pesquisa e debates opondo à eleição para ocupação da função o concurso para assunção de cargo na carreira dos profissionais do Magistério. Entretanto, o último posicionamento não vingou, na maior parte do território nacional, uma vez que ainda é forte a cultura de indicação por parte do Poder Executivo, que parece ver na prática, uma forma de controle dos sistemas de ensino que tem grande poder de capilaridade e alcance às famílias das comunidades locais.

No entanto, nas duas últimas décadas, a realização de eleições como prática para definir o candidato a ocupar a função de diretor de escola, permitiu a realização de uma série de experiências, visando a qualidade nos serviços prestados à população. É evidente que apenas a realização de eleições não garante o processo de gestão das escolas com qualidade. Portanto, vários dispositivos foram criados visando definir os critérios que melhor atenderiam o determinado pela legislação, pautada pelos resultados obtidos no cotidiano das unidades escolares e que se referem ao perfil exigido (experiência e formação), ao período de gestão (incluindo o dispositivo da reeleição), realização de cursos e provas, apresentação de plano de trabalho, eleição propriamente dita, dentre outros.

Tendo vivido, como profissionais e pesquisadoras, os processos desenvolvidos tanto na rede estadual quanto na rede municipal de Ponta Grossa, com base em tais experiências, pretende-se analisar como historicamente se constituiu o processo de seleção de diretores do sistema de ensino do município, destacando os fatores que contribuíram para a sua qualificação com a participação efetiva de segmentos dos profissionais da Educação e do Sindicato dos Servidores Municipais e, também, do desenvolvimento do processo de formação continuada de diretores, sendo a última, especificamente no período 2005-2008.

\section{Os desafios para os gestores no sistema de ensino e nas unidades escolares}

São inúmeros os desafios que se apresentam para os sistemas de ensino na construção de políticas públicas vistas como uma série de ações encadeadas, de atendimento às demandas postas pelas comunidades atendidas por tais ações, respeitando-se suas peculiaridades econômicas, culturais e educativas. 
As políticas públicas são conformadas por questões de caráter teórico, político e técnico que definem a direção de decisões adotadas, encaminhamentos traçados, avaliações realizadas. Todos estes fatores se processam num cenário específico, das políticas públicas sociais, no qual se insere a Educação, entendida como responsabilidade do Estado, ultrapassando ações descontinuadas de Governo como usualmente se coloca na tradição brasileira.

Nesta perspectiva existem, nos sistemas de ensino, diferentes papéis a serem exercidos pelos gestores educacionais e escolares, em âmbitos muito diferenciados, que abrangem órgãos executivos, além das unidades escolares, seja da Educação Infantil ou seja do Ensino Fundamental.

O panorama profissional do magistério exige, na atualidade, o desenvolvimento de programas de formação de gestores para assumirem tais funções, sendo este espaço de formação continuada ainda pouco atendido pelas políticas educacionais, dada a complexidade e diferenciada organização dos sistemas/redes de ensino no país.

No âmbito dos órgãos centrais dos sistemas de ensino os gestores têm sido majoritariamente indicados pela via político-partidária, considerando-se o currículo e experiência profissional; para as unidades escolares a seleção de profissionais para ocupar a função de diretor(a) tem ultrapassado apenas a perspectiva anteriormente apontada centrando-se no caráter técnico, por meio de cursos de gestão escolar, provas e/ou eleições, com a participação da comunidade escolar e/ou circundante à escola.

Além dos processos de indicação/seleção de gestores um dos grandes desafios para os sistemas de ensino é a formação continuada com programas efetivos de acompanhamento das práticas gestoras desenvolvidas e reflexão sobre os referenciais que as fundamentam.

A temática é complexa e, em termos educacionais brasileiros, é ainda bastante restrito o estudo sistemático sobre o seu desenvolvimento nos sistemas de ensino.

Considerando esses aspectos neste texto apresentam-se algumas questões próprias da seleção e formação continuada dos gestores escolares da rede municipal de ensino de Ponta Grossa. A primeira, abrangendo as diretoras do Ensino Fundamental e a segunda, atingindo a todas as diretoras da rede municipal de ensino, incluindo a Educação Infantil.

\section{Âmbitos de atuação dos gestores nos sistemas de ensino}

Como já afirmado anteriormente os gestores podem atuar em nível de sistema de ensino tanto nos órgãos centrais quanto nas unidades escolares. Sua atuação deve estar fundamentada por referenciais teóricos que priorizam a democratização das relações e dos espaços institucionais e a descentralização do sistema e dos procedimentos. No entanto, culturalmente os sistemas de ensino no país têm uma gestão de caráter autoritário, que se reproduz, em escala, para as instâncias imediatamente inferiores. Para isso contribui a indicação política para funções de gestão, forma de ascensão definida/praticada na ampla maioria dos sistemas de ensino. Tal situação só pode ser revertida, a longo prazo, pela democratização das relações sociais vigentes no país e 
pelo trabalho massivo de formação de profissionais, contribuindo para que a indicação política seja fundada no mérito da formação e da experiência profissional. Além disso, o recrutamento de profissionais para atuar em funções de gestão deve obedecer os ditames da Lei de Diretrizes e Bases da Educação Nacional.

Considerando a perspectiva da democratização e da descentralização, como aspectos fundamentais para a atuação dos gestores nos órgãos centrais dos sistemas de ensino, entende-se que os mesmos passam a ser orientadores das escolas, respeitando o espaço dos profissionais que atuam nas mesmas, discutindo encaminhamentos e estratégias para atender às necessidades locais/regionais, afastando-se da postura de impor normas que consideram acertadas e adequadas à determinadas situações escolares/educativas. Para tanto, algumas questões devem ser garantidas:

- clareza quanto às metas a serem atingidas; devem ser conhecidas as políticas educacionais propostas;

- existência de um currículo básico comum;

- previsão de avaliação sistemática das unidades escolares e de seus alunos;

- garantia de recursos financeiros suficientes;

- transparência, correção e equidade na aplicação dos recursos da Educação;

- garantia de fruição dos recursos humanos e financeiros para a escola;

- rompimento das barreiras burocráticas;

- existência de programa de formação inicial e contínua dos profissionais da

- educação (professores, gestores e pessoal de infra-estrutura);

- produção de dados para definição de indicadores e metas;

- incentivo à participação por parte da sociedade civil e da comunidade circundante à escola (MACHADO, 1999).

No que concerne aos diretores das escolas, no contexto da descentralização do sistema e da democratização das relações no interior da unidade escolar, cabe-lhes o papel de investir maciçamente na qualidade de seu trabalho, que deve ser primordialmente voltado para o aspecto pedagógico, pois não há justificativa para a existência de uma escola com aspectos físicos de primeira linha e com um alto índice de evasão e repetência.

Isso significa um desrespeito à finalidade e responsabilidade social da escola pública. Várias são as tarefas do gestor escolar, compromissado com a qualidade de ensino:

- empenho sistemático para a melhoria das condições de ensino da escola, atentando para as necessidades de formação permanente de seus quadros docente e administrativo;

- estabelecimento de canal de comunicação permanente com o sistema central e no interior da escola para divulgação e troca de informações;

- acompanhar o desenvolvimento de seu plano de ação e do 
projeto pedagógico da escola;

- interação com a sociedade civil organizada e com a comunidade circundante à escola;

- acompanhar e avaliar o desenvolvimento do currículo escolar;

- participar da avaliação dos serviços prestados à comunidade, tanto do ponto de vista pedagógico quanto administrativo;

- apresentar as demandas da comunidade escolar e providenciar, junto aos gestores do sistema central, medidas para a sua consecução;

- aplicar de forma correta, transparente e equânime as verbas da escola;

- pautar-se, na avaliação dos profissionais da escola, por critérios de formação e mérito profissional (MACHADO, 1999).

Indicado o âmbito de atuação dos gestores educacionais e escolares é importante refletir sobre os desafios que enfrentam os sistemas de ensino na tarefa de selecionar profissionais para assumir a gestão das unidades escolares. $\mathrm{Na}$ rede municipal de ensino de Ponta Grossa, em 2005, a seleção de diretores foi normatizada por um processo que se iniciou com a aplicação de questionário para levantamento da opinião de professores, pedagogas, funcionários e diretores visando à construção de critérios para a seleção dos gestores: definição do tempo do mandato e do estatuto da reeleição, relação entre a eleição e possíveis aperfeiçoamentos da gestão da escola e resultados pedagógicos obtidos, acompanhamento do Plano de Gestão proposto e características da gestão no cotidiano da escola.

Os dados coletados indicaram a concordância com os critérios propostos quanto à lotação, formação inicial, experiência profissional, preponderante atenção ao processo pedagógico da escola, necessidade de formação continuada específica e de apresentação de plano de trabalho para a função, articulação entre o critério de eleição e decorrente aperfeiçoamento dos resultados pedagógicos obtidos. A duração do mandato e a possibilidade de reeleição foram aspectos que se revelaram polêmicos apresentando diferentes resultados nos segmentos consultados.

O mandato de 4 anos foi considerando o ideal pelas diretoras, obtendo um índice alto $(88,4 \%)$; já para as pedagogas ocorreu o equilíbrio entre mandatos de 4 e 3 anos (respectivamente 34, 6\% e 46, 6\%) predominando o último; as professoras votaram majoritariamente na duração de mandato de 2 anos (67\%); os funcionários apresentaram posição próxima das professoras indicando $56 \%$ para 2 anos, 29,3\% para 4 anos e $10 \%$ para 3 anos de mandato. A análise dos dados permite afirmar que professores e funcionários apresentaram significativo posicionamento em direção a um mandato de 2 anos, enquanto dentre os pedagogos se apresentou um equilíbrio entre mandatos de 3 e 4 anos, sendo o mandato de 4 anos posição majoritária entre as diretoras.

A possibilidade de reeleição sem restrição (indefinidamente), foi acatada pela maioria das diretoras em exercício sendo que a maioria das pedagogas optou por 2 mandatos alternados $(46,6 \%)$, com forte presença do mandato de 2 mandatos consecutivos $(34,6 \%)$; as professoras indicaram a reeleição sem restrição (43\%), seguida por 2 mandatos consecutivos (34, 1\%); já os funcionários apontaram a 
reeleição sem restrição (56\%) como a melhor opção, apresentando diferença entre 2 mandatos consecutivos (34\%) e 2 mandatos alternados $(21,5 \%)$.

Articulando as duas questões anteriormente analisadas pode-se afirmar que as diretoras optaram por mandatos de 4 anos de duração sem restrição à reeleição. Este posicionamento apresentou-se coerente com o universo pesquisado, uma vez que grande número de diretoras já detinha mais de um mandato na direção da escola, indicando a pretensão de permanecer na função. Entre as pedagogas a opção majoritária foi de 2 mandatos alternados com duração de 3 anos; as professoras e os funcionários indicaram, em sua maioria, um mandato com duração de 2 anos, com possibilidade de reeleição sem restrição.

Os resultados apontados pelos profissionais indicam que a redução do tempo de permanência no cargo, em cada mandato, seria uma possibilidade salutar de, por meio de eleições, referendar o trabalho desenvolvido pela diretora da escola. É importante destacar que tal posicionamento foi um indicativo da possibilidade de alternância no poder, embora o alto número de votos na opção sem restrição quanto à reeleição, com mandatos de 4 anos, se apresentasse como uma contraposição à tal possibilidade. Podese inferir, nesta perspectiva, que a forte cultura das rotinas escolares tenha produzido um peso considerável, relativo à acomodação na situação vigente no interior da unidade escolar.

De posse de tais resultados ocorreu, a seguir, a constituição de Comissão Consultiva, pela Secretária Municipal de Educação, visando ampliar o universo de discussão das questões anteriormente analisadas. A Comissão Consultiva foi composta por representantes do Conselho Municipal de Educação, do Conselho Municipal do FUNDEB, do Sindicato dos Servidores Públicos Municipais, de duas instituições de ensino superior que mantêm o curso de Pedagogia (uma pública e uma privada) e da SME.

Como resultado do trabalho realizado a Comissão Consultiva sugeriu à Secretária de Educação um mandato com 4 anos de duração com a possibilidade de uma reeleição, como garantido constitucionalmente para os demais cargos eletivos do poder executivo municipal. Quanto à formação, sugeriu-se a graduação em Pedagogia, como afirmado na LDB no 9394/96, ou outra licenciatura complementada por curso de pósgraduação stricto sensu (mestrado ou doutorado). Os posicionamentos foram acatados e garantidos no Decreto Municipal $n^{\circ}$ 590/05 de 24/11/2005 que também definiu a necessidade da mantenedora oferecer curso de Gestão Escolar a todas as pessoas que desejassem se candidatar ao cargo de diretor na rede municipal de ensino, com 40 horas de duração.

O processo eleitoral apresentou o seguinte resultado: 11 escolas não tiveram candidatas inscritas para o curso; 99 professoras participaram do curso e da avaliação; 84 foram aprovadas; 15 professoras não atingiram $80 \%$ na avaliação que era $o$ percentual mínimo, conforme o Decreto Municipal no 590/05. Dentre elas, 5 diretoras em atuação. Cabe registrar, que três escolas tiveram candidatas aprovadas com certificação do ensino superior, sem reconhecimento do MEC, o que se contrapunha ao exigido na legislação (as mesmas participaram das eleições e assumiram o cargo protegidas por liminar do Poder Judiciário, sendo mantidas como diretoras após o julgamento do mérito); 3 escolas não atingiram o quorum mínimo (50\%) de votantes, invalidando as eleições. Assim, totalizou-se 17 escolas que necessitaram de indicação de 
diretoras pela Secretária de Educação, situação referendada pela legislação (na gestão anterior, 29 diretoras foram indicadas após as eleições de 2001).

O processo de seleção, constituído pela realização do curso de gestão, prova de conhecimento com questões teóricas e resolução de casos, elaboração de plano de trabalho, eleições, posse e assinatura de termo de compromisso, apresentou como resultado a renovação de $70,3 \%$ do quadro de diretores para o mandato 20052009.

Registre-se que, devido à longa permanência de algumas diretoras na função, ocorreu forte reação de uma minoria, ao Decreto Municipal $n^{\circ}$ 590/05, no tocante ao critério da reeleição, que impediu a recondução destas profissionais. As mesmas se movimentaram junto à Câmara de Vereadores e ao Prefeito para tentar reverter tal definição.

No entanto, a transparência imprimida ao processo pela participação de todos os envolvidos, tanto da comunidade escolar quanto dos representantes da sociedade civil organizada na Comissão Consultiva, inviabilizaram todas as tentativas de promover interferências descabidas, não encontrando ressonância nos poderes Legislativo ou Executivo municipais.

\section{Cotidiano e formação continuada dos gestores escolares}

Encerrado o processo de seleção a SME definiu, para o ano de 2006, o processo de formação continuada das diretoras da rede municipal programando a realização de grupos de estudos com um encontro mensal. As atividades desenvolvidas privilegiaram a metodologia de estudo sistemático de um texto pré-programado (encaminhado com uma semana de antecedência para valorizar a reflexão e discussão sobre as temáticas definidas) e relato de casos do cotidiano escolar para aplicação do referencial teórico estudado e divulgação de experiências desenvolvidas na rede municipal.

Outro aspecto importante da formação continuada foi a manutenção do convênio da Secretaria Municipal de Educação com o Instituto Ayrton Senna (IAS) que inicialmente desenvolvia, por meio de sua área de Educação Formal, o Programa Circuito Campeão destinado ao acompanhamento do ensino regular, com monitoramento de dados focados na freqüência, leitura de livros, realização de tarefas e cumprimento das matrizes curriculares referentes aos dois ciclos de aprendizagem ${ }^{1}$. Em decorrência de tais princípios serem coerentes com os objetivos e metas propostos para o Plano Pluri-anual 2005-2009 da SME foram definidos, respeitando-se a cultura escolar, os seguintes indicativos como linha de trabalho: cumprimento integral dos dias letivos previstos, elevação dos índices de freqüência de professores e alunos, atenção/diminuição dos índices de desistência/distorção idade-série; alunos lendo aos 7 anos (ano intermediário do $1^{\circ}$ Ciclo), alunos concluindo a $4^{\text {a }}$ série com plano de estudos para concluir o Ensino Fundamental.

O trabalho realizado sempre valorizou e incentivou as diretoras de unidades escolares do Ensino Fundamental e da Educação Infantil para que registrassem e divulgassem as práticas gestoras desenvolvidas, ensaiando o exercício de autoria e impedindo que os resultados alcançados pelas soluções cotidianas, específicas à cada 
unidade escolar, se ocultassem do conjunto da rede municipal. Para incentivar tais procedimentos, criando a cultura do registro e divulgação, a SME desafiou um grupo de diretoras a se inscrever em eventos científicos nacionais e regionais. Nesta direção, a SME apresentou um novo desafio às diretoras quando, em 2006, a rede municipal de ensino recebeu, do Ministério da Educação/Instituto de Estudos e Pesquisas Educacionais Anísio Teixeira-MEC/INEP, o Prêmio Nacional de Referência em Gestão Educacional. $\mathrm{O}$ valor de $\mathrm{R} \$ 50.000,00$, do prêmio, foi destinado à edição de uma coleção de livros contendo o relato das práticas gestoras da rede municipal de ensino tanto das escolas quanto dos CMEIs, visando que cada diretora pudesse refletir sobre seu plano de ação-o proposto e o executado- e, também tivesse a oportunidade de prestar contas (um dos princípios da gestão pública: publicizar os resultados) sobre o trabalho realizado.

Todo o esforço despendido na formação continuada, tanto por parte da equipe da SME quanto por parte das gestoras escolares, tem trazido como resultado a apresentação de relatórios melhor qualificados e, principalmente, a profissionalização da gestão dos resultados, apresentados pelos alunos, sugerindo as intervenções necessárias, desejandose que as mesmas sejam menos de caráter emergencial e mais de caráter preventivo.

Esta é a direção que se tenta imprimir nas ações de formação continuada, na perspectiva da democratização e da descentralização. Esta última, coloca o desafio do poder de decidir, que subsume um aspecto muito importante que é a gestão com responsabilidade, uma vez que exige o pleno conhecimento da realidade, baseada em dados fidedignos, a democratização do debate e da tomada de decisão e, ainda, o compromisso com os resultados alcançados, assim como as possíveis correções de rumos.

\section{Referências}

FERREIRA, N. S. C. (Org.). Gestão democrática da educação: atuais tendências, novos desafios. São Paulo: Cortez, 2003.

HÖFLING, E. M. Estado e políticas (públicas) sociais: políticas públicas e educação. Cadernos CEDES, n. 55, p. 30-41, 2002.

IAS. INSTITUTO Ayrton Senna. Foco: área de educação formal do IAS, ago. 2007.

In: Encontro de Secretários Municipais de Educação. [s.1.], abr. 2005.

LÜCK, H. Perspectivas da gestão escolar e implicações quanto à formação de seus gestores. Em Aberto, Brasília, v. 17, n. 72, [s.d.].

MACHADO, A L. Referências básicas para a formação dos gestores educacionais. In: Gestão educacional: tendências e perspectivas. São Paulo: CENPEC, 1999.27

PARRO, V. H. Eleição de diretores: a escola pública experimenta a democracia. Campinas: Papirus, 1996. 
RIBAS, M. H.; LUPORINI, T. J. Políticas e gestão da educação: formação e seleção de diretores no Estado do Paraná In: ANPED. Anais..., PUC-PR, 2004.

SCHENECKENBERG, M. O princípio democrático na atuação do diretor da escola: um estudo comparativo entre diretores eleitos e reeleitos da Rede Pública Municipal de Ensino de Ponta Grosa. Tese (Doutorado) - Universidade Estadual de Campinas, Campinas, 2005.

Notas:

${ }^{1} \mathrm{O}$ município adota a progressão por ciclos de aprendizagem sendo: $1^{\circ}$ ciclo (6 a 8 anos); $2^{\circ}$ ciclo $(9$ e 10 anos) e a retenção ocorre aos 8 anos ( $3^{\circ}$ ano do $1^{\circ}$ ciclo) e aos 10 anos ( $2^{\circ}$ ano do $2^{\circ}$ ciclo); em 2005 , foi universalizado o ensino fundamental de 9 anos na rede municipal de ensino.

Recebido em: 22/10/11

Aprovado em: 15/11/11 